\title{
Original article \\ Role of serum cardiac Troponin-I for risk stratification in first attack in acute myocardial infarction
}

\author{
Sahabuddin Joarder $\mathrm{M}^{1}$, Jafarullah $\mathrm{M}^{2}$, Moinuddin $\mathrm{A}^{3}$
}

\begin{abstract}
Introduction: Cardiac troponin-I (cTnI) is known to have the highest specificity and analytic sensitivity for detection of myocardial injury; it is used both as diagnostic and prognostic marker. This study was aimed to confirm this idea. Subjects \& methods: This prospective observational study included 60 patients of 40 to 65 years age range diagnosed as acute myocardial infarction. The mean ages were $50 \pm 8$ years and $53 \pm 8$ years in Q -wave AMI and non Q-wave AMI respectively. Male and female patients included were 86.7\% and 13.3\%; BMI was 25.3 \pm 1.5 . Results: Study showed troponin-I $7.53 \pm 0.086 \mathrm{ng} / \mathrm{ml}$ in Q wave and in non Q-wave AMI was $6.38 \pm 0.64 \mathrm{ng} / \mathrm{ml}$ after 24 hours of attack of AMI without any significant difference between two groups $(\mathrm{P}>0.05)$. The mean troponin-I within 9 hours of attack, were $1.60 \pm 0.80 \mathrm{ng} / \mathrm{ml}$ and $2.7 \pm 1.4 \mathrm{ng} / \mathrm{ml}$ in stable and unstable group respectively and the difference found statistically significant $(\mathrm{P}<0.05)$. The mean troponin-I between $9-24$ hours of attack were $2.90 \pm 1.20 \mathrm{ng} / \mathrm{ml}$ and $4.90 \pm 3.20 \mathrm{ng} / \mathrm{ml}$ in stable and unstable group respectively and the difference found statistically significant $(\mathrm{P}<0.01)$. The mean troponin-I in unstable group after 24 hours was $9.20 \pm 4.30 \mathrm{ng} / \mathrm{ml}$ which was more than between $9-24$ hours and the difference was significant $(\mathrm{P}>0.001)$. In clinicopathological outcome evaluation 37 patients had troponin-I level $>1.5 \mathrm{ng} / \mathrm{ml}$ in which 29 patients developed unstability and 8 patients were stable. Conclusion: Serum cTnI is better and more characteristic biomarker for risk prediction and prognosis evaluation in AMI patients.
\end{abstract}

Key words: Cardiac Troponin-I, acute myocardial infarction, risk stratification.

\section{Introduction}

Ischaemic heart disease is a major global health problem and the most common cause of premature morbidity and mortality among men in the developed world ${ }^{1}$. Mortality rates attributed to IHD vary between countries. The WHO MONICA study monitoring IHD and risk factors in 38 thousand population from 21 countries in four continents showed that age standardized annual event (Fatal and non fatal) rates in 1985 to 1987 in men range from $915 / 100,000$ in North korelia, Finland to $76 / 100,000$ in Beijing, China.
In women it ranges from $256 / 100,000$ in Glasgow, UK to 30/100,000 in Catalonia, Spain. Events rates and case fatality rates for men and women in the same populations were strongly correlated. The IHD mortality data from the MONICA study are broadly consists with the routine published mortality data ${ }^{2}$. AMI is the leading cause of death in Bangladesh in the $4^{\text {th }}$ decade of life. So in our population myocardial infarction emerged as a major killer and in the long run a major cause of mortaliy $^{3}$. The world health organization

1. Md. Sahabuddin Joarder, Associate Professor, Department of Biochemistry, Z. H. Sikder Women's Medical College

2. Md. Jafarullah , Professor (C.C.), Department of Biochemistry, Medical College for Women \& Hospital, Uttara, Dhaka-1230.

3. Moinuddin Ahmed, Assistant Professor, Medical College for Women \& Hospital, Uttara, Dhaka-1230. Corresponds to:

Dr. Md. Jafarullah MBBS, MD, Professor (C.C.), Department of Biochemistry, Medical College for Women \& Hospital, Uttara, Dhaka-1230. 
lists three criteria for the diagnosis of AMI; chest pain, electrocardigaphic changes and increases in Biochemical markers ${ }^{4}$. Lack of diagnostic sensitivity and specificity of clinical and conventional markers prevent or delay the treatment, leading to the undue suffering to the patients. Until recently, the conventional first step in diagnosing AMI patients whose symptoms are compatible with ischaemia is a careful history and physical examination ${ }^{5}$.

Confirmatory diagnosis by ECG and measurement of serum creatinine kinase (CK) isoenzyme is necessary ${ }^{6}$. The ECG remains the cornerstone for the early diagnosis of the ischaemia showing ST segment change within seconds of the ischaemic insult in approximately $60 \%$ of patients. However, the ECG can be inconclusive in the remaining $40 \%$ of cases, which makes the ECG of low sensitivity ${ }^{7}$. Moreover the traditional enzyme markers for the detection of myocardial injury are also of questionable sensitivity and specificity $^{8}$. National academy of clinical biochemistry and the international federation of clinical chemistry recommended myoglobin/CK-MB isoform for early detection of AMI and cTnI /CK-MB mass for definitive diagnosis of $\mathrm{AMI}^{9}$. Facilitation of earliest possible diagnosis is very important for the treatment and risk stratification of patients with suspected coronary artery disease. AMI patients is there fore more confidently predicted on an increased cardiac troponin concentration in blood and regarded as the most cardiac specific of currently available biochemical markers for the diagnosis of myocardial injury ${ }^{10}$.

\section{Materials \& Methods}

This prospective observational case study included 60 patients age range 40-65 year diagnosed as active myocardial infarction by ECG and cardiac markers within 24 hours of attack and admitted in CCU of Zainul Haque Sikder cardiac care and research enter, Dhaka. Study was conducted in the department of biochemistry, BSMMU during January 2002 to December 2003. Ethical approval was taken from the authority of the concerned hospital and informed consent was taken from all participants. Three consecutive blood samples were collected from each of the study subjects. First one within 9 hours of attack, second sample between 9-24 hours of attack and third one after 24 hours of attack but within the day of admission were taken and proceed. All tests were performed on the day of collection. All patients were followed up upto 30 days of attack by taking history; clinical examination, Biochemical investigation and imaging technique.

Then according to these findings patients were categorized into stable and unstable group. Estimation of serum cardiac troponin I (cTnI), estimation of serum creatinine kinase $\mathrm{MB}$ isoenzyme (CKMB) and echocardiography were done. Data was expressed as mean \pm SD. Statistical difference between different groups was calculated by students t-test and ANOVA. Statistical analysis was performed with the soft ware SPSS version 11.0 for windows.

\section{$\underline{\text { Result }}$}

Total 60 patients were included in this study of which 30 were Q wave AMI and 30 were non $\mathrm{Q}$ wave AMI. The male patients included in this study were $86.7 \%$ and female were $13.3 \%$ with the male; female ratio 6.5:1. The different base line characteristics of study subjects in respect of Q-wave AMI and non Q-wave AMI which did not differ. The mean BMI $25.3 \pm 1.5$, $25.8 \pm 1.7$; Pulse $84 \pm 12$, b/m, $82 \pm 11 \mathrm{~b} / \mathrm{m}$; MBP $91 \pm 15 \mathrm{mmHg}, 95 \pm 13 \mathrm{mmHg} ; \mathrm{FBS}$ $117 \pm 3, \mathrm{mg} / \mathrm{dl}, 114 \pm 51 \mathrm{mg} / \mathrm{dl}$ were found in Q-wave AMI and non Q-wave AMI respectively (Table-I). 
Table-I: Baseline characteristics of the study subjects on admission.

\begin{tabular}{lcc}
\hline \multicolumn{1}{c}{ Characteristics } & $\begin{array}{c}\text { Q-wave AMI } \\
(\mathbf{m} \pm \text { SD) }\end{array}$ & $\begin{array}{c}\text { Non Q-wave AMI } \\
(\mathbf{m} \pm \text { SD) }\end{array}$ \\
\hline Age (years) & $50 \pm 8$ & $53 \pm 8$ \\
Sex Male $\quad$ Female & $26(86.7 \%)$ & $26(86.7 \%)$ \\
BMI (kgm $\left.{ }^{2}\right)$ & $4(13.3 \%)$ & $4(13.3 \%)$ \\
Pulse (beats/min) & $25.3 \pm 1.5$ & $25.8 \pm 1.7$ \\
MBP (mmg) & $84 \pm 12$ & $82 \pm 11$ \\
FBS (mg/dl) & $91 \pm 15$ & $95 \pm 13$ \\
\hline
\end{tabular}

Table-II: Troponin-I level at different time of attack in stable group of study subjects.

\begin{tabular}{lccc}
\hline \multicolumn{1}{c}{ Time of sampling } & Troponin-I (ng/ml) & \multicolumn{2}{c}{$\mathbf{t} / \mathbf{p ~ v a l u e s}$} \\
\hline Within in 9 hrs of attack (S1) & $1.60 \pm 0.80$ & - & - \\
Between 9-24 hrs (S2) & $2.90 \pm 1.20$ & S1 vs S2 & $4.677 /<0.01$ \\
After 24 hrs (S3) & $4.40 \pm 3.70$ & S2 vs S3 & $1.465 />0.05$ \\
\hline
\end{tabular}

Results are expressed as mean \pm SD. Independent sample ' $t$ ' test was performed to calculate statistical difference

Table-III: Troponin-I level at different time of attack in unstable group of study subjects.

\begin{tabular}{lccc}
\hline \multicolumn{1}{c}{ Time of sampling } & Troponin-I (ng/ml) & \multicolumn{2}{c}{ t/p values } \\
\hline Within in 9 hrs of attack (S1) & $2.70 \pm 1.40$ & - & - \\
Between 9-24 hrs (S2) & $4.90 \pm 3.20$ & S1 vs S2 & $5.000 /<0.001$ \\
After 24 hrs (S3) & $9.20 \pm 4.30$ & S2 vs S3 & $7.149 />0.001$ \\
\hline
\end{tabular}

Results are expressed as mean \pm SD. Independent sample ' $t$ ' test was performed to calculate statistical difference.

Table IV: Evaluation of troponin-I with respect to the clinico-pathological outcome (within 30 days) outcome of study subjects.

\begin{tabular}{|c|c|c|c|c|c|c|}
\hline \multirow{2}{*}{\multicolumn{2}{|c|}{ Biomarker level }} & \multicolumn{2}{|c|}{ Follow-up } & \multirow{2}{*}{ Total } & \multirow{2}{*}{$\mathbf{x}^{2}$} & \multirow{2}{*}{$\mathbf{P}$} \\
\hline & & Stable & Unstable & & & \\
\hline \multirow[b]{2}{*}{ Troponin-I } & $>1.5 \mathrm{ng} / \mathrm{ml}$ & 8 & 29 & 37 & \multirow{2}{*}{7.544} & \multirow{2}{*}{$<0.01$} \\
\hline & $\leq 1.5 \mathrm{ng} / \mathrm{ml}$ & 13 & 10 & 23 & & \\
\hline
\end{tabular}


The mean troponin-I in Q-wave AMI within 9 hours, between 9-24 hours \& after 24 hours were $2.81 \pm 2.22, \quad 5.26 \pm 0.61$ and $7.53 \pm 0.86 \mathrm{ng} / \mathrm{ml}$ and those in non Q-wave AMI were $2.35 \pm 0.39, \quad 3.93 \pm 0.58$ and $6.38 \pm 0.64 \mathrm{ng} / \mathrm{ml}$ respectively without any significant difference between two groups $(\mathrm{P}>0.05)$ (Figure-1).

Mean troponin-I within 9 hours were $1.60 \pm$ $0.80 \mathrm{ng} / \mathrm{ml}$ and $2.7 \pm 1.40 \mathrm{ng} / \mathrm{ml}$ in stable and unstable group respectively and the difference found statistically significant $(\mathrm{P}<0.05)$. The mean troponin-I between 9-24 hours were $2.90 \pm 1.20 \mathrm{ng} / \mathrm{ml}$ and $4.90 \pm$ $3.20 \mathrm{ng} / \mathrm{ml}$ in stable and unstable group respectively and the difference found statistically significant $(\mathrm{P}<0.01)$. The mean troponin-I after 24 hours were $4.40 \pm 3.70$ $\mathrm{ng} / \mathrm{ml}$ and $9.20 \pm 4.30 \mathrm{ng} / \mathrm{ml}$ in stable and unstable group respectively and the difference found statistically significant $(\mathrm{P}<0.05)$ (Figure-2).

Troponin-I in stable group within 9 hours and between 9-24 hours were $1.6 \pm 0.8$ and $2.90 \pm 1.20 \mathrm{ng} / \mathrm{ml}$ respectively and the difference found statistically significant $(\mathrm{P}<$ 0.01). The mean troponin-I in stable group after 24 hours was $4.40 \pm 3.70 \mathrm{ng} / \mathrm{ml}$ which was apparently more than that of 9-24 hours. But the difference was not significant $(\mathrm{P}>$ 0.05) (Table-II).

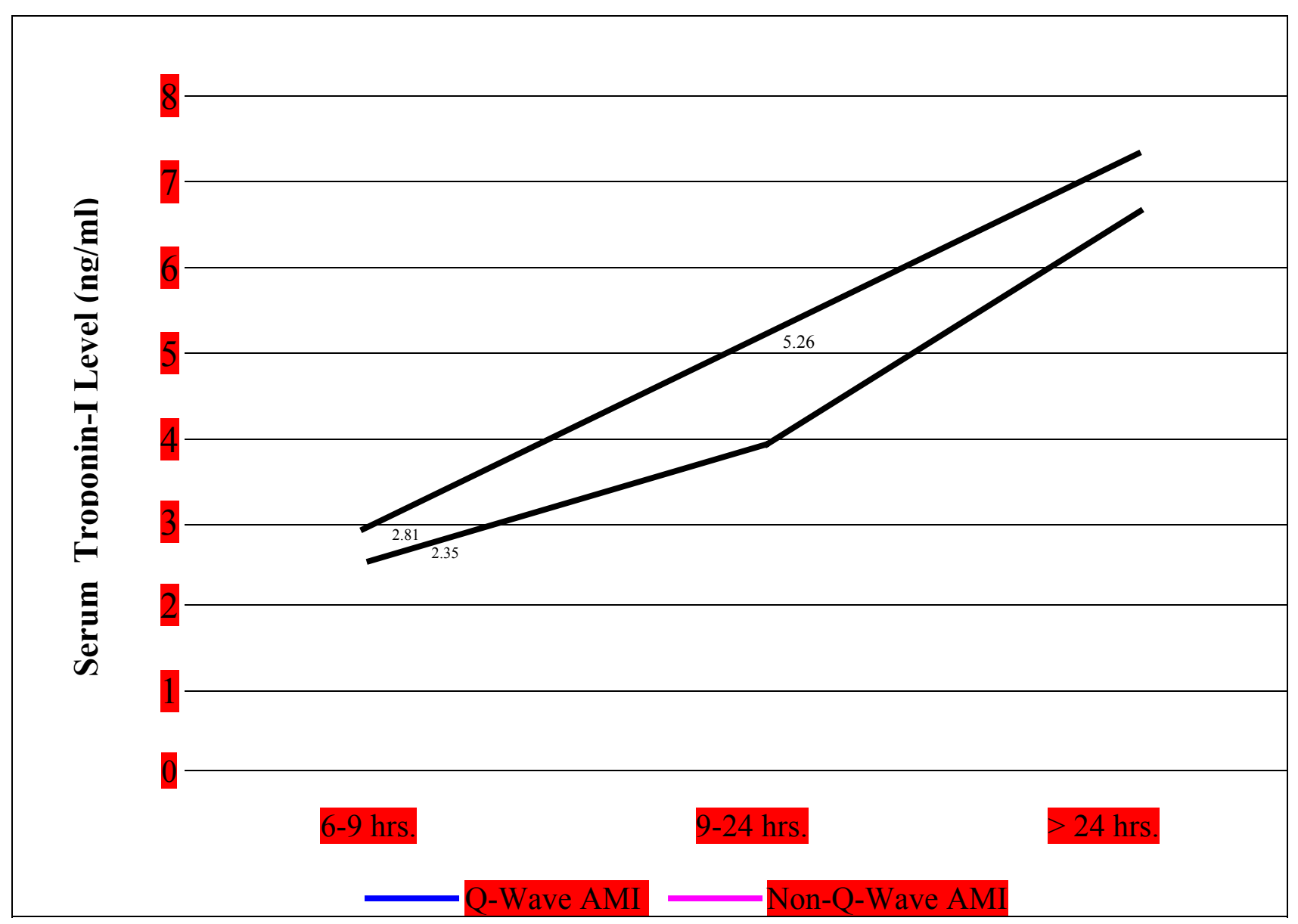

Figure:-1: Comparison of troponin-I in Q-wave AMI and non Q-wave AMI with respect to the time of cardiac attack. 


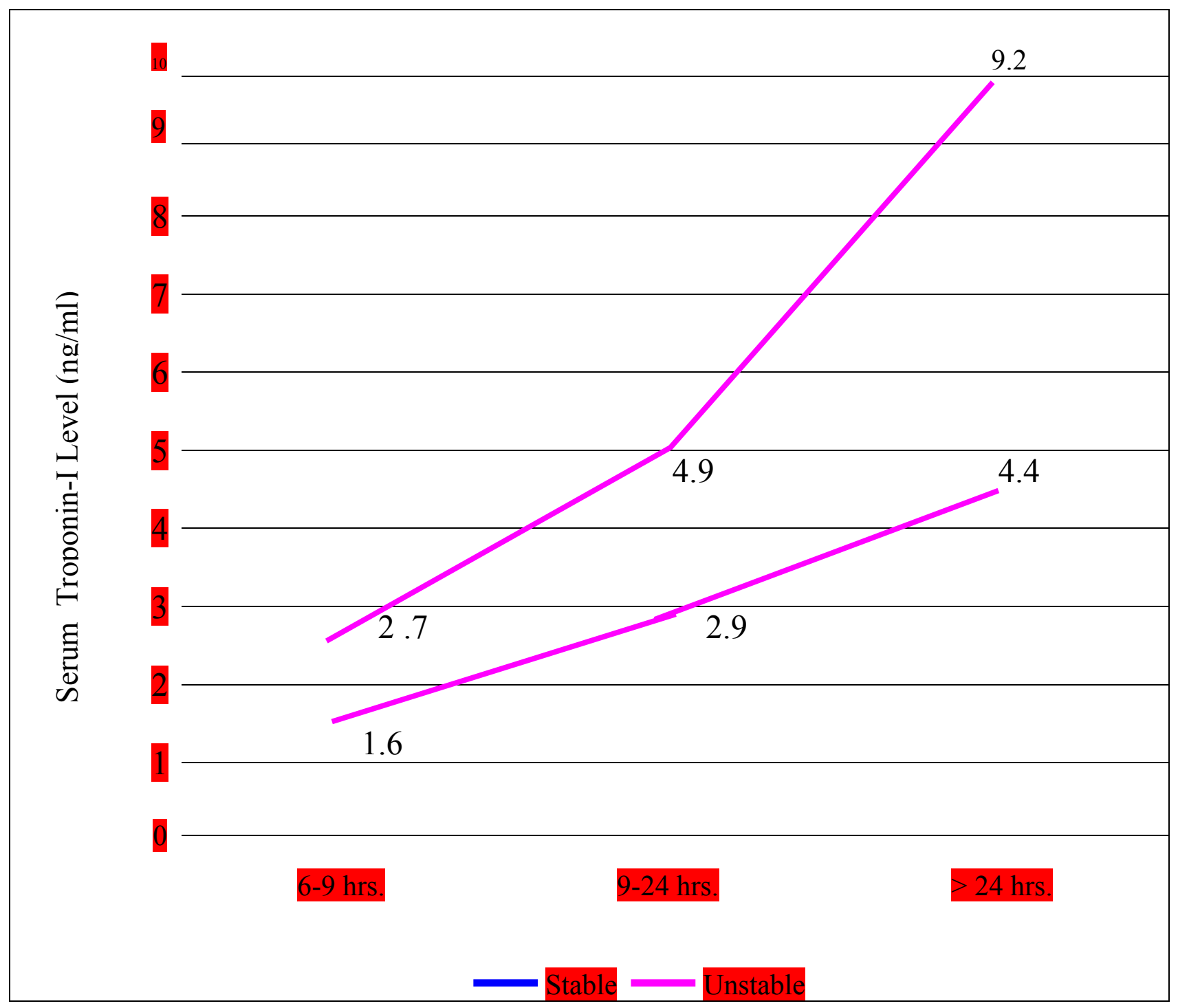

Fig:-2: Comparison of troponin-I between stable and unstable group at different time of attack.

Troponin-I in unstable group within 9 hours $\&$ between $9-24$ hours were $2.70 \pm 1.40$ and $4.90 \pm 3.20 \mathrm{ng} / \mathrm{ml}$ respectively and the difference found statistically significant $(\mathrm{p}<$ $0.001)$. The mean troponin-I in unstable group after 24 hour was $9.20 \pm 4.30 \mathrm{ng} / \mathrm{ml}$ which was apparently more than that of 9-24 hours and the difference found statistically significant $(\mathrm{P}<0.001)$ (Table-III).

During evaluation of troponin-I with respect to the clinico-pathological outcome of study subjects within 30 days 37 patients had troponin-I level $>1.5 \mathrm{ng} / \mathrm{ml}$ in which 29 patients developed unstability and 8 patients were stable. But 23 patients had troponin-I level $\leq 1.5 \mathrm{ng} / \mathrm{ml}$ in which 10 patients become unstable and 13 patients were stable. This difference of clinicopathological outcome with respect to higher and lower value of troponin-I was statistically significant $(\mathrm{P}<0.01)$ (Table-IV). 


\section{Discussion}

In this prospective observational study we have evaluated the serum cardiac troponin-I for risk stratification in post myocardial infarction of patients first ever attacked by MI. Total 60 patients with a recent history of chest pain diagnosed as Q-wave AMI (30) and non Q-wave AMI (30) by conventional E. C. $\mathrm{G}$ and cardiac markers within 24 hours of attack and admitted in CCU were selected for the study.

Although Q-wave AMI claimed to have more myocardial damage than non Q-wave AMI. Our findings of serum cTnI failed to

support this since the concentration of these cardiac markers was not different between two groups. This was further supplemented by our findings of no differences between two groups with respect to this adverse cardiac outcome. This might be due to the fact that the myocardial damage in Q-wave AMI were just enough to make Q-wave in ECG but not yet to cause hectic release of cardiac markers. Test systems for cardiac troponin-I (cTnI) provide the highest specificity and analytic sensitivity for detection of myocardial injury and serum cTnI helps to assess the true complication of the patients ${ }^{11}$. Several other studies also have documented the prognostic superiority of the serum cTnI for early and safe risk stratification of patients with acute chest pain $^{12}$.

The study conducted by Bodi stated that troponin-I is better as a diagnostic tool ${ }^{13}$. Braunwald recommended that troponin-I as the best cardiac markers for diagnostic and prognostic purpose. The uses of cardiac troponin will undoubtly increases the number of event recorded in particular trial because of increase sensitivity for detecting $\mathrm{MI}^{14}$. In our study we have also evaluated the serum cTnI with respect to a definite cut off value and the clinico-pathological outcome. At cTnI $>1.5 \mathrm{ng} / \mathrm{ml}$ the tendency of unstability found to be significantly more than that at $\mathrm{cTnI} \leq 1.5 \mathrm{ng} / \mathrm{ml}$. Milenko et al in their study with serum cTnI cut off value $0.4 \mathrm{ng} / \mathrm{ml}$ showed that patients with cTnI levels of $0.4 \mathrm{ng} / \mathrm{ml}$ or greater had a significantly increased risk of death compared with patients with cTnI less then $0.4 \mathrm{ng} / \mathrm{ml}$. The risk of death they found to increase further with increasing troponin-I levels ${ }^{15}$.

Steinberg et al used serum cTnI concentration for risk stratification in 885 patients with acute MI and they found the elevated troponin-I levels greater than 1 $\mathrm{ng} / \mathrm{ml}$ to be positively correlated with death within 30 days and correlation between elevated troponin-I and death was Independent of CK-MB levels ${ }^{16}$. Antman et al showed that mortality rate was consistently higher among patients with cardiac troponin-I more than $0.4 \mathrm{ng} / \mathrm{ml}$ than those with cTnI less than $0.4 \mathrm{ng} / \mathrm{ml}^{17}$.

Therefore our findings in line with many other previous studies suggest that serum cTnI is better and more characteristics biomarker for risk prediction in AMI patients. AMI patients with raised serum cTnI and its progressively increasing pattern are more prone to develop adverse cardiac outcome in subsequent couple of weeks.

\section{Conclusion}

Cardiac troponin-I is the most specific and sensitive marker of myocardial cell injury and therefore have replaced creatinine kinase MB. Cardiac troponin-I has high specificity for cardiac injury because it is not found in skeletal muscle during neonatal development and adulthood. Cardiac troponin-I is released into blood within hours of the onset of symptoms of myocardial infarction and that it remains elevated for several days of post-infarction. Measurement of cardiac troponin-I levels provides sensitive and specific determination 
of myocardial injury over a wide diagnostic time window. We suggest identical study with greater sample size involving different hospital nation wide. Moreover the study might include troponin isoforms to make out much greater objective view for cardiac marker in risk stratification of AMI.

\section{Reference}

1) Wright RA, Fox KA. Prognosis in ischaemic heart diseases. Medicine International 1993; 6(24):384-388.

2) Shaper GA. Epidemiology of ischaemic heart disease. Medicine International 1993; 6(24):379-383.

3) Khondokar RK, Hossain D, Hossain M. Retrospective analysis of acute myocardial infarction. Bang Heart $J$ 1987; 1:14.

4) Jaffe AS, Lant Y, Parvin CA. Comparative sensitivity of cardiac troponin I and lactate dehydrogenase isoenzymes for diagnosing acute MI. Clin Chem 2000; 42:1770-1776.

5) Chalif PO. Troponin $\mathrm{T}$ or troponin I or CK-MB. Eur Heart J, 1992; 1:16-24.

6) Adam JE III, Bordar GS, DavilaRoman VG. Cardiac troponin-1: A marker with high specificity for cardiac injury. Circulation 1993; 88: 101-106.

7) Rouan GW, Lee TH Cook EF. Clinical characteristics and outcome of acute myocardial infraction in patients with initially normal or nonspecific electrocardiograms, $A M \quad J$ Cardiol 1989; 64:1087-1092.

8) Panteghini M. Biochemical assessment of myocardial damage with new diagnostic tools, Cardiologia 1999; 44:419-425.

9) WuAHB, Apple FS, Gibter WB. National Academy of clinical biochemistry standards of laboratory practice, Clin Chemistry 1999; 45:1104-1121.

10) McCarthy BD, Wong JB Seiker HP. Detecting acute cardiac ischaemia in the emergency Department. $J$ Gen Intern Med 1990; 5:365-373.

11) Christian Hamm W. Cardiac troponin elevations in patients without acute coronary syndrome, Circulation 2002; 106(23):2871-2872.

12) Sato GS, Poole WR, Muller JE. Electrocardiographic and clinical criteria for recognition of acute MI, Am J cardiol 2001; 52:936-942.

13) Bodi VV. Is troponin I useful for predicting in hospital risk for unstable angina patients in a community hospital? Rev Esp Cardiol 2002; 55 (2):100-106.

14) Braunwald M, Goldman L. Serum enzyme essays in the diagnosis of acute myocardial infarction. Recommendations based on a quantitative analysis, Ann Intern Med 2000; 105:221-233.

15) Milenko JR Kannel WB, Feinleich M. Clinical feature of unrecognized myocardial infarction, Am J cordial 1999; 32:1-7.

16) Steinberg WJ, Balfe D1, Kustner HG. Decline in the ischaemic heart disease mortality rates of South Africans, South African Med J 1998; 74:547550.

17) Antman EM, Tanasijevic MJ, Thompson B. Cardiac-specific troponin-1 levels to predict the risk mortality in patients with ACS, New Engl J Med 1996; 335:1342-1349. 